\title{
A. LA TRANSICIÓN POLÍTICA EN LA REPÚBLICA DOMINICANA: DEL AUTORITARISMO DE NUEVO TIPO A LA DEMOCRACIA FORMAL
}

JACQUELINE JIMÉNEZ POLANCO. IRELA (Rep. Dominicana) 



\section{A. LA TRANSICIÓN POLITICA EN LA REPÚBLICA DOMINICANA: DEL AUTORITARISMO DE NUEVO TIPO A LA DEMOCRACIA FORMAL}

POR

JACQUELINE JIMÉNEZ POLANCO

IRELA (Rep. Dominicana)

NUEVO MODELO AUTORITARIO:

EL RÉGIMEN DE BALAGUER (1966-1978)

En los años setenta, las profundas transformaciones sociales experimentadas por la sociedad dominicana durante la consolidación del régimen autoritario de Joaquín Balaguer, entraron en contradicción con el autoritarismo como forma de dominación, frente a la incapacidad del régimen para procesar la complejidad de los procesos que se estaban produciendo.

A su llegada al poder mediante las elecciones fraudulentas de $1966^{1}$, Balaguer intenta afianzar su proyecto político autoritario en base a una actividad represiva dirigida a destruir cualquier práctica encaminada a desplazarle del poder.

De ahí que la violencia y la represión, como mecanismos de desmovilización social y política, constituyen los elementos fundamentales,

1 La elección de Balaguer en 1966, fue el resultado de la legitimación de los Estados Unidos a un proceso electoral caracterizado por la presión de los militares contra la oposición, luego de la intervención norteamericana que puso fin a la guerra civil de 1965, detonada por el golpe militar que frustró el gobierno democrático de juan Bosch a menos de un año de su elección. 
tanto del terror sistemático dirigido a desarticular cualquier mecanismo de acción colectiva (incluida la "oposición legal») como de la imposición reeleccionista de Balaguer mediante los fraudes electorales de 1970 y 1974.

La constitución en los años sesenta del Partido Reformista (PR), en tanto mecanismo de contención de las pasiones políticas, promueve un movimientismo en el que la participación pasiva de la sociedad como «mayoría silenciosa», en una organización de masa ideológicamente monolítica, subordinada a la voluntad del líder carismático, veda las prácticas democráticas, tanto hacia el interior como hacia el exterior del partido.

Internamente, el sentimiento intenso de solidaridad que está por encima de las diferencias internas y de la potencial diversidad de intereses, a la que se sobrepone la lealtad como causa común: el partido es el líder, constituye la base de la ideología monolítica del PR. Mientras, a nivel externo, la política de adhesión colectiva al partido se desarrolla fundamentalmente en base a la despolitización de las masas urbanas marginadas y de las masas campesinas, sin más derecho a la participación que la emisión del voto cada cuatro años.

Así, mientras la creación de la Cruzada del Amor, organización de caridad que vincula a los marginados con el PR y con el gobierno, constituye la forma de agregación clientelar de las masas pobres urbanas al régimen; la movilización desde arriba de las masas campesinas (tradicionalmente conservadoras) mediante la creación del Movimiento Agrario Reformista (MAR), promueve la desarticulación del campesinado, al tiempo que se crean expectativas en la tenencia y propiedad de la tierra mediante la promulgación de las Leyes de Reforma Agraria.

Por otro lado, la creación a finales de los años sesenta de la Comisión Nacional de Desarrollo (CND), que integra a industriales, banqueros, hacendados, burócratas y sobre todo al sector empresarial, sirve de mecanismo de participación en el régimen de los sectores económicamente dominantes, cuyas formulaciones relativas a proyectos de leyes, planes de desarrollo.o simples medidas administrativas, sustentan los planes de "progreso" y de "desarrollo económico" del proyecto autoritario de $\mathrm{Ba}$ laguer.

De esta manera logra Balaguer el grado de solidez suficiente para alcanzar el nivel de autonomía que le permite regirse en sus doce años por la lógica del autoritarismo excluyente e incluyente: mediante la inversión del proceso de movilización, desarticulando el movimiento popular y anulando la función mediadora de los partidos políticos, y me- 
diante la "reorganización» de un Estado jerárquico y apolítico, con participación consultiva basada en la representación corporativa.

Todo ello sustentado en unas Fuerzas Armadas leales a la figura de Balaguer y a su capacidad de dirección y control del monopolio de la fuerza legal, que mantiene mediante la rotación de la jerarquía militar como mecanismo de equilibrio y de unificación, y vía la integración de los militares en la burocracia estatal y sus beneficios clientelistas, con lo cual consolida su poder sobre éstos.

A nivel económico y social, el régimen de Balaguer aplica una política antiobrera, que en nombre de una "paz laboral» que asegura las inversiones extranjeras (norteamericanas) y las de la nueva burguesía industrial, sobreexplota la fuerza de trabajo en condiciones infrahumanas, aplicando como contrapartida una congelación salarial que perdura durante los primeros ocho años del régimen (1966-1974).

De modo que al corporativismo verticalista de inclusión de la élite burguesa en el proceso de decisiones del Estado, se une una política antisindical y antiobrera excluyente, dirigida a la promoción de un desarrollismo en el que el Estado no interviene como árbitro entre las grandes empresas y los sindicatos, sino que el propio Estado se convierte en un gran inversor en base a fuertes inyecciones de capital público (préstamos y donaciones).

Y mientras la política autoritaria de masas de Balaguer y el Partido Reformista (PR) se afianza, la principal fuerza opositora, el Partido Revolucionario Dominicano (PRD), experimenta (a finales de los sesenta) un proceso de radicalización ideológica sustentado en la tesis desarrollada por su máximo líder, Juan Bosch, de la Dictadura con Respaldo Popular, mediante la cual niega la validez del proceso electoral como mecanismo para llegar al poder y abjura de la democracia representativa.

La tesis de Bosch, que pretende estructurar un nuevo modelo de organización partidaria que pusiese en tela de juicio al régimen y que socavase su base de apoyo mediante un impacto deslegitimador común que trascendiera a otras organizaciones políticas, especialmente de izquierda, provoca la división del PRD y la consolidación del liderazgo de José Francisco Peña Gómez ${ }^{2}$, mientras Bosch organizaba su nuevo partido, el Partido de la Liberación Dominicana (PLD).

2 Peña Gómez emergió como líder carismático en la década de 1960, dada la autoridad política que había adquirido frente a las distintas facciones del PRD, así como por su poder de aglutinamiento de las masas populares que empezó a destacar durante el golpe militar de 1963 y los acontecimientos políticos que siguieron hasta la insurrección civil de 1965. 
La oposición antisistema del $\mathrm{PRD}^{3}$ cuenta, en un principio, con la adhesión del Partido Comunista Dominicano (PCD) y del Movimiento Popular Dominicano (MPD), izquierda y extrema izquierda, respectivamente, al tiempo que determina la abstención de dichos partidos en las elecciones de 1970.

Pero el alto grado de estabilidad que caracteriza el primer período de gobierno de Balaguer (1966-1970), resultado de la mecánica interna del régimen - represión y modernización-y del importante nivel de legitimación sustentado básicamente en el apoyo de las Fuerzas Armadas y del campesinado, entra en crisis a mediados de los años setenta, siendo el resultado de varios factores.

En primer lugar, el uso excesivo de la violencia política por parte de las Fuerzas Armadas, que radicalizaron la represión tras el desembarco guerrillero de Francisco Caamaño Deñó (líder de la revolución constitucionalista de 1965) en 1973, unido a la violenta represión ejercida por la Juventud Reformista Anticomunista (JRAD) o Banda Colorá, organización paramilitar a la que Balaguer llamaba los «incontrolables" y que se destinaba a asesinar y a torturar a los dirigentes políticos de izquierda radical.

A todo esto se sumaba la situación de ilegalidad en que se encontraban los partidos de izquierda moderada, mientras en el PRD el rechazo de los sectores tradicionales (vinculados a la burguesía) al proyecto de Bosch generaba un proceso de relegitimación, fortalecido por la integración del PRD a la Internacional Socialista.

De esta manera, mientras el régimen eliminaba la oposición política al PR de la izquierda marxista, la relegitimación interna del PRD trascendia a las masas, produciéndose una corriente de relegitimación recíproca que coadyuvaba a la preponderancia del centro frente a la derecha, eliminando la tendencia centrífuga que había caracterizado la política partidista dominicana durante la oposición antisistema del PRD.

En segundo lugar, en la sociedad dominicana de los años setenta, se estaba generando un proceso de mayor estructuración de la sociedad

3 Entiendo que la posición asumida por el PRD sustentada sobre la tesis de la "Dictadura con respaldo popular" de Bosch, era una oposición antisistema, porque pretendía enfrentar al régimen de Balaguer con una falta de apoyo de determinados partidos políticos (oposición por cuestiones concretas), al tiempo que mediante una oposición por principio abjuraba el PRD de Bosch, de la democracia representativa, creando un máximo de distancia ideológica entre el sistema y su partido. Para fines teóricos de la oposición antisistema, véase Giovanni Sartori, Partidos y Sistemas de Partidos I, Alianza Editorial, Madrid, 1987, págs. 168 y ss. 
civil, resultado de los cambios operados en la estructura demográfica y social, producto del crecimiento económico y del proceso de modernización que el propio régimen autoritario había promovido.

Pero ese proceso de estructuración no operaba como mecanismo generador de relaciones de interdependencia entre las instituciones sociales y económicas, ya que no existía la acción colectiva, ni como mediadora, ni como organizadora de los intereses sectoriales.

Las transformaciones sociales no habían alcanzado al Estado, de manera que se produjese un aumento de funciones nuevas que respondiesen a las demandas sociales corporatizadas o promovidas por los partidos y que creasen una interdependencia recíproca entre el Estado y la sociedad civil.

De ahí que la polarización política que inclinaba la balanza electoral hacia el PR, resultado de la ausencia de consenso y de legitimidad (legalidad más justificación moral) del régimen autoritario de Balaguer, que al manipular los mecanismos electorales (vía la militarización de los procesos o el fraude electoral) forzaba la abstención del PRD, había alcanzado su punto más álgido en las elecciones de 1974.

Ciertamente, la reelección fraudulenta de Balaguer en 1974 provocó una reacción de rechazo en sectores importantes de la población, que se puso de manifiesto en la abstención del $44,5 \%$ de los electores frente al llamado hecho por la oposición encabezada por el PRD, a lo que siguió la realización de movimientos de protesta contra el continuismo y el reclamo de participación política, en tanto expresiones de deslegitimación del régimen autoritario.

Estos factores determinaron la aplicación de medidas de apertura que promovieron la desradicalización política del régimen en su último período (1974-1978), favoreciendo la integración política de algunos partidos de izquierda moderada, mediante el reconocimiento legal por la Junta Central Electoral del PLD de Bosch, del PCD de Narciso Isa Conde y de la Unión Patriótica (UPA), liderada por Franklyn J. Franco. Mientras, a nivel sindical, la Secretaría de Estado de Trabajo otorgaba personalidad jurídica a la Central General de Trabajadores (CGT).

Pero, frente a los cambios, el modelo autoritario había perdido su capacidad de procesamiento de las demandas de una sociedad en rápida transformación, que presionaba por una mayor participación social y política. Lo que sí se estaba produciendo y en gran escala, era la consolidación vía burocrática de la corrupción como el "mejor" mecanismo para garantizar el sostenimiento de una política clientelar, que no tenía miramientos ante el proyecto de enriquecimiento de unos pocos frente al empobrecimiento de muchos. 
Esto se explica porque durante los doce años de Balaguer, el Estado desarrollista prevaleció sobre el Estado social, ya que la promoción del "crecimiento" económico a toda costa estuvo privilegiada con respecto a la cuestión social.

De ahí que a finales de los años setenta, la quiebra del autoritarismo, tanto en su expresión tradicional (clientelismo, prebendas, represión, liderazgo personalista, desarrollismo estatista, etc.) como en su expresión renovadora (constitución de una burguesía empresarial, expansión de la clase media, civilidad del régimen, etc.), y el nacimiento de un régimen democrático capaz de procesar las demandas sociales, se hacía impostergable.

Esto es así porque durante el tercer período de Balaguer (19741978) la idea de un cambio de régimen era la respuesta a una alteración sustantiva en el interior y en el entorno del régimen autoritario, a la que éste era incapaz de adaptarse ${ }^{4}$.

Se produjeron fuertes tensiones entre el Estado y la sociedad civil en lo relativo al uso del poder, en las que los actores sociales presionaban desde abajo en contra de la exclusión de los sectores populares de la participación política, mientras los sectores burgueses y medios reclamaban una mayor participación en las decisiones del Estado y los partidos políticos exigían un grado de legalidad que permitiese su participación en el poder mediante mecanismos competitivos.

Las luchas internas por el poder constituían el eje de acción de los partidos políticos, motivadas por el debilitamiento del régimen autoritario y la posibilidad de ascenso al control del Estado que permitiese, para algunos (la élite del PR), la sustitución del líder y la permanencia del partido de gobierno en el poder y, para otros (el PRD), el cambio político que aniquilara el autoritarismo y diera paso a un régimen democrático.

De esta forma se iniciaban las condiciones formales para el proceso de transición hacia la democracia, que tendría su punto de partida en las elecciones de 1978, con lo cual se daba paso a la construcción de la democracia política.

4 Julián Santamaría utiliza estos conceptos en su estudio: «Transición controlada y dificultades de consolidación: el enfoque español», pág. 375, en Julián Santamaría (comp.), Transición a la Democracia en el Sur de Europa y América Latina. Centro de Investigaciones Sociológicas, Madrid, 1982. 


\section{PROCESO ELECTORAL DE 1978: \\ TRANSICIÓN CONTROLADA HACIA LA DEMOCRACIA}

Durante la precampaña electoral de 1978, las luchas intrapartidarias generadas por las aspiraciones políticas de las élites dirigentes colmaban el escenario político del cambio hacia la democracia en las principales organizaciones partidistas.

En el Partido Reformista (PR), la lucha intrapartidaria se inició cuando frente a la designación (por Balaguer) de Fernando Álvarez Bogaert como candidato a la vicepresidencia, sus pretensiones de ser el futuro sucesor de Balaguer ocasionaron tensiones en las altas esferas del partido, las cuales fueron dirimidas mediante su "renuncia", ante la negativa de Balaguer de ceder su papel de árbitro y líder supremo $y$, en cuanto tal, único con capacidad y potestad para decidir los candidatos a cargos electorales. El impasse fue resuelto mediante la designación, por tercera vez consecutiva, de Carlos Rafael Goico Morales como compañero de boleta de Balaguer, con lo cual frenaba el "líder" las aspiraciones de sucesión de su delfín.

En el Partido Revolucionario Dominicano (PRD), la lucha por el poder se desarrolló entre grupos denominados "tendencias" que tuvieron su raíz en la IX Convención de 1977, en la que se enfrentaron dos sectores importantes que se procuraban el liderazgo político del partido: el sector tradicional, representado por Antonio Guzmán, quien había sido candidato a la vicepresidencia por el PRD en las elecciones de 1966 y candidato a presidente por el Acuerdo de Santiago en 1974, y el sector moderno, representado por Salvador Jorge Blanco.

El triunfo de Guzmán y su elección como candidato a la presidencia frente a Jorge Blanco, que fue designado por negociación intrapartidaria como candidato a Senador por el Distrito Nacional, saldó la lucha entre las dos tendencias, mientras mediante negociación entre Jacobo Majluta (que había quedado en tercer lugar en la primera vuelta) y Guzmán, Majluta fue designado compañero de boleta de Guzmán.

Estas disputas intrapartidarias tuvieron un efecto positivo en la población votante, que benefició al PRD, ya que evidenciaban actitudes democráticas hacia el interior del partido nunca antes vistas por el pueblo dominicano, acostumbrado a los liderazgos personalistas y excluyentes que han marcado históricamente el quehacer político del país.

Por otro lado, la sociedad se encontraba expectante frente a los posibles cambios que podría generar el ascenso al poder del principal par- 
tido de la oposición, ya que, por primera vez después de más de una década, la sociedad asistía a una verdadera lucha por el poder político ${ }^{5}$.

Así que mientras el PR permanecía anquilosado en una estructura partidaria de servilismo y obediencia al liderazgo personalista y vertical de Balaguer, estático frente a los cambios sociales e incapaz de procesar los conflictos generados por dichos cambios, el PRD emergía, después de una larga trayectoria como partido opositor a un régimen cerrado a la disidencia (primero Trujillo, después Balaguer), como una oposición distinta, renovadora frente al PR.

Pero no obstante haber creado las condiciones institucionales para que se produjese la reorganización de la oposición política y su participación vía mecanismos electorales en la lucha por el poder estatal, Balaguer (confiado en su liderazgo carismático) no planeaba perder las elecciones. Por lo que, ante la inminente victoria del PRD sobre el PR, se realizaron en las altas esferas del Estado una serie de acciones que intentaron frustrar el proceso electoral, a fin de que Balaguer pudiera retener el poder por cuarta vez.

Las maniobras para frustrar la transición democrática tuvieron su punto de partida en la suspensión del conteo de los votos por la Junta Central Electoral (JCE) la madrugada del 17 de mayo de 1978, cuando tropas del Ejército Nacional, por orden de la élite militar leal a Balaguer, intervinieron las oficinas del máximo órgano electoral, forzando la suspensión del conteo de votos.

Al «madruganazo» siguió la acción represiva de los militares contra los funcionarios y empleados de la JCE con fines de alterar los resultados electorales en favor del PRD.

Factores externos e internos impidieron la realización de un golpe militar que impusiera a Balaguer al margen de la voluntad popular. De una parte, la presión norteamericana y de la Internacional Socialista y, de otra, la movilización social y las manifestaciones de sectores empresariales en señal de apoyo al gobierno del presidente electo, Antonio Guzmán ${ }^{6}$.

5 Las últimas elecciones libres celebradas en la República Dominicana después de la caída de la dictadura trujillista, fueron las de 1962 que llevaron al poder al PRD por primera vez.

- EI PRD ingresó a la Internacional Socialista en los años setenta, después de la escisión provocada por la tesis de la "Dictadura con respaldo popular" de Bosch, a la que se opuso la orientación electoralista de Peña Gómez. 
En este contexto se iniciaba la transición controlada hacia la democracia, cuya fragilidad estuvo en gran parte condicionada por la negociación entre las partes en conflicto y por la acomodación en el nuevo régimen, de las fuerzas que habían sido sustituidas.

\section{DEMOCRACIA FORMAL: EL GOBIERNO DE ANTONIO GUZMÁN (1978-1982)}

El proceso electoral de 1978 determinó el ascenso al poder del PRD, que, después de una larga trayectoria como partido opositor al autoritarismo ${ }^{7}$, se convertía en partido de gobierno, en unas condiciones políticas y sociales adversas a la realización en su primer mandato, de un proyecto democrático sólido que promoviese, de una parte, la realización de reformas institucionales que consolidaran el sistema democrático $y$. de otra, la promoción de cambios sustanciales en el orden económico y social, dirigidos a alcanzar un nivel importante de democratización sustantiva (economía redistributiva y justicia social).

En primer lugar, el pacto o negociación entre un PRD elegido por segunda vez vía mecanismos democráticos y un PR derrotado después de más de dos décadas en el poder vía mecanismos fraudulentos y violentos, sostenido por la lealtad de unas Fuerzas Armadas defensoras del status quo impuesto por el régimen autoritario de Balaguer, fue el resultado de un hecho conocido como el "fallo histórico", mediante el cual, después de celebradas las elecciones, la JCE adjudicó al PR la mitad de los votos emitidos en cuatro provincias que hablan sido ganadas por el PRD, lo que permitiría al PR controlar el Senado.

El "fallo histórico» se convirtió, de esta forma, en el mecanismo "transaccional" que condicionaría la transición política hacia la democracia, a la limitación constitucional que supondria el control del poder legislativo y del judicial por el régimen anterior ${ }^{8}$.

7 EI PRD fue fundado en La Habana (Cuba) en 1942 por un grupo de exiliados de la dictadura trujillista, entre los cuales se encontraba Juan Bosch como primer partido opositor al trujillismo (1930-1961), pasando a ser el principal oponente del balaguerismo (1966-1978).

a Mediante el fallo histórico, el PR pasó a controlar el Senado con el $59,26 \%$ de los escaños frente al $40,74 \%$ del PRD, lo que constitucionalmente le permitiría controlar el poder judicial, así como designar los miembros del colegio electoral (JCE). Artículo 23 de la Constitución de 1966. 
En segundo lugar, la lucha interna librada en el PRD por las tendencias, si bien introdujo un elemento innovador en el liderazgo dominicano de tradición carismática autoritaria, constituyó posteriormente un elemento perjudicial para la consolidación de la democracia: el control del poder del Estado por un partido político dividido internamente en oposición y gobierno. Pues la lucha por el control del partido, sostenida por las tendencias jorgeblanquista y guzmancista, se tradujo en una lucha dentro de los poderes del Estado, que no solamente obstaculizó la realización del principal proyecto de reforma constitucional propuesto por el PRD en su programa de gobierno (la no reelección presidencial), sino que impidió el alcance y conclusión de proyectos sociales beneficiosos para la sociedad.

La imposibilidad del reparto del poder entre las dos tendencias promovió una lucha constante por la apropiación futura del poder del Estado vía electoral, que a su vez generó fuertes críticas y ataques del partido hacia el gobierno y del gobierno hacia el partido, relegando a un segundo plano, y para el futuro, las conquistas democráticas, sobre todo aquellas de carácter social y económico.

En tercer lugar, la sociedad, que había confiado sus esperanzas de cambio político y social en el proyecto democrático del PRD, veia frustradas sus demandas, al no ser éstas canalizadas vía representación estatal, de la cual había carecido durante los doce años del autoritarismo balaguerista.

Esto así, porque las interpelaciones democráticas que habían caracterizado al PRD en la oposición fueron sustituidas por prácticas clientelistas y paternalistas que distanciaron la élite perredeísta de los sectores populares, cuya agregación por el partido como sujetos de acción política había constituido la base esencial de su proyecto democratizador de los años sesenta.

La política clientelista del presidente Guzmán, que le garantizó el cumplimiento de sus "compromisos" con sectores burgueses y medios, permitiendo a los primeros consolidar sus riquezas y aumentar sus medios productivos y sirviendo a los segundos de mecanismo de movilidad social vertical en una economía limitada, estuvo unida a una política económica "expansiva» dirigida a priorizar la distribución del ingreso y el aumento del empleo, en ausencia de cambios importantes en el proceso de acumulación ${ }^{9}$.

9 La generación de empleos y el aumento salarial, fueron realizados mediante el endeudamiento público y las emisiones de dinero inorgánico, lo que expandió el proceso inflacionario en desproporción con el poder adquisitivo de la mayoría de la población. 
Lo cual, unido a otros factores, tanto internos como externos, profundizó la crisis económica heredada del fracaso del modelo desarrollista, que frente a la incapacidad del Estado para resolverla y sus efectos negativos en los grandes sectores populares, creó fuertes sentimientos de deslegitimación que pusieron en peligro la estabilidad del régimen ${ }^{10}$.

Las tensiones entre el régimen y la sociedad, así como las tensiones entre el gobierno y el partido, sustentadas en la hipertrofia del Estado (como resultado de una política redistributiva basada en la corrupción y el clientelismo) y en la lucha de tendencias, determinaron la crisis del primer gobierno perredeísta, lo que provocó actitudes de adhesión de un número importante de la población electoral hacia los demás partidos: el PR y el PLD.

El más beneficiado sería el PLD, por su proyecto de gobierno sustentado en la honestidad como mejor mecanismo para afrontar la corrupción y la crisis económica, ya que el PR se había quedado anquilosado en sus estructuras partidarias, sin ofrecer proyecto alguno de democratización.

\section{CRISIS DE LAS INSTITUCIONES DEMOCRÁTICAS: EL GOBIERNO DE SALVADOR JORGE BLANCO (1982-1986)}

En 1982 se produce la vuelta del PRD al control y dirección del Estado, esta vez mediante la victoria electoral del sector que tradicionalmente había representado el ala izquierda del perredeísmo, Jorge Blanco en el Ejecutivo y Peña Gómez en el liderazgo del partido $-y$ en cuanto tal-, al lado del presidente, como parte importante de un proyecto de gobierno, en el que la "concentración de todas las fuerzas nacionales" daría inicio a la implantación de un nuevo período democrático que, además de garantizar el disfrute de las libertades públicas (proyecto de gobierno del PRD en 1978), promovería la democracia económica y social.

La participación del PRD en el control del poder estatal, la no reelección, el desarrollo económico del país y el respeto a los derechos hu-

10 El alza de los precios del petróleo, que generó aumentos importantes en los precios de la gasolina, desencadenó una huelga del transporte público en agosto de 1979, a la que siguieron otras en 1980 y en 1981. 
manos, eran los cuatro puntos básicos del programa del «Gobierno de Concentración Nacional», que, de cumplirse, resultaria en importantes avances en el desarrollo, confirmación y asentamiento del sistema democrático, lo que implicaría el salto definitivo hacia la racionalización y modernización de las relaciones entre el Estado y la sociedad civil.

Mediante las reformas contenidas en el Proyecto de Ley de Revisión Constitucional presentado por Jorge Blanco en su discurso de juramentación, se interpelaba a la población sobre la continuación del proceso de transición política, mediante la institucionalización de los mecanismos democráticos (independencia del poder judicial, consagración constitucional de la no-reelección, etc.). Mientras, la moralidad y la eficiencia constituían los elementos discursivos de la política de democratización social y política, a fin de combatir la corrupción y la crisis económica.

No obstante, y para el enorme pesar de la sociedad dominicana, que con su participación electoral había otorgado los mecanismos de legitimación necesarios para el ascenso del PRD al poder, el Proyecto de Ley de Revisión Constitucional jamás llegó a aprobarse, aun cuando el partido contaba con la mayoría absoluta en el Congreso (Cámara de Diputados y Senado), que fue utilizado, por el contrario, como escenario de las tensiones entre las tendencias, que ya habían convertido en tradición el traspaso de su lucha intrapartidaria por el poder a los órganos del Estado.

De esta forma, la lógica de los intereses grupales intrapartido, se impuso a la lógica de la racionalidad democrática, impidiendo al Congreso Nacional realizar su función de contrapeso del Ejecutivo.

Muestra de lo anterior fue la crisis del Senado en 1984, producida por el enfrentamiento entre grupos que se disputaban la presidencia del órgano parlamentario, considerándose cada uno con potestad para constituir su propio Senado.

Las funciones del Estado fueron descuidadas para encontrar una salida al impasse mediante la búsqueda de explicaciones doctrinales de «juristas notables», que dijesen públicamente a qué grupo o tendencia pertenecía la presidencia del Senado. Por supuesto (y lamentablemente para la consolidación institucional del sistema), cada sector tenía sus propios "notables", lo que fortalecía cada vez más el uso de los mecanismos clientelares y personalistas por parte de los representantes del Estado, para legitimar sus intereses.

La política económica y social basada en la moralidad y la austeridad se tradujo en "eficiencia laboral" y "sacrificio del consumo", que implicaba, de una parte, el aumento de la jornada ordinaria de trabajo $y$, de 
otra, la aplicación de un programa de "ajuste» dirigido a reducir el nivel de vida de la población a fin de cumplir con los compromisos de la deuda externa. Para tales fines, el gobierno redujo el salario real de los trabajadores públicos, prohibió algunas importaciones y autorizó a los bancos a operar en el mercado de los dólares, a lo que se sumó la aplicación de medidas de incentivo al sector privado dedicado a las actividades especulativas.

En enero de 1983, el gobierno firmó un «acuerdo de facilidad ampliada" con el FMI como vía para completar el programa de "ajustes" económicos iniciado en su toma de posesión, a fin de «resolver» la crisis económica.

Las medidas aplicadas fueron: reducción del gasto público y el consumo mediante la aplicación de impuestos indirectos; liberalización de los precios, reducción de las importaciones, restricción de los créditos, congelación de los salarios y traspaso al mercado paralelo de divisas de los pagos de importaciones de bienes y servicios, lo que provocó un aumento inmediato de los índices de precios al consumidor $y$ un aumento en la tasa de cambio del dólar por el peso dominicano.

Estas últimas medidas económicas detonaron la explosión popular desorganizada de mayor trascendencia política y social que se había producido en el país desde la guerra civil de 1965, las protestas populares de abril de 1984, expresión de violencia contra los altos niveles de pobreza distributiva, que fue saldada con centenares de muertos y miles de detenidos, resultado del uso indiscriminado de la fuerza por parte de las autoridades militares y su justificación por el gobierno.

Los efectos deslegitimadores de la política económica y de la violencia militar contra las demandas sociales estuvieron acompañados de una agudización del proceso de desmoralización en la dirección política del Estado iniciada por el anterior gobierno.

A todo esto se añadia la pérdida del "mito fundacional» del PRD mediante un proceso de desarticulación ideológica y organizativa, generado por su participación en la actividad política, no en función del servicio a la sociedad, sino en base a los beneficios que otorgan la clientela y el personalismo.

La pasión por el poder, entendida por las élites politicas que habían dirigido los destinos del Estado dominicano en transición como un apetito afanoso, posesivo y violento por el control del poder del Estado, en perjuicio de los derechos civiles y políticos de las mayorías que habían determinado su ascenso, debilitaba cada vez más la creencia en el sistema democrático. Mientras, en la sociedad dominicana, la «miseria 
de la desmoralización" y la "desmoralización de la miseria" promovian el desencanto.

Al PRD le falló la estrategia, tanto en su función como partido de gobierno, como hacia el interior de la organización.

Por una parte, la reestructuración de formas autoritarias que han caracterizado la tradición política dominicana generó un Ejecutivo hipertrofiado, en el que la cada vez mayor autonomización del personal estatal produjo un poder incontrolado en sus funciones, en tanto el Legislativo reducía su actividad a legitimar las actuaciones del primero, y el Judicial, relegado a su tradicional condición de "enajenado", sucumbía ante las decisiones de los otros dos.

De otra parte, el PRD, cuya tradición de partido democrático — unificador de las masas en torno a las ideas de participación y justicia social- había anclado en la memoria colectiva, resultado de su participación en la dirección de la lucha democrática de clases en los años sesenta, y cuya estrategia de participación como principal partido opositor al autoritarismo balaguerista lo había convertido en el principal actor político de las transformaciones sociales que se produjeron en los años setenta, hasta llevarlo a la dirección del Estado en transición. Terminó siendo víctima de su propia lógica partidaria, de la que no pudo salvarlo ni siquiera el liderazgo carismático de Peña Gómez, cuya autoridad como líder principal del partido había entrado en crisis como parte de un todo.

REELECCIÓN DE BALAGUER EN LAS ELECCIONES DE 1986: ¿DEBILITAMIENTO DE LA DEMOCRACIA POLITICA O PROSPECTOS DE LA FUTURA CONSOLIDACIÓN?

El fracaso del PRD como partido en el gobierno y como gobierno del partido, tanto por los graves errores cometidos en la política económica e institucional de sus dos períodos de gobierno como por su desorganización interna - la lucha de tendencias-, inclinó la balanza electoral hacia su más fuerte contendiente, el PR, mientras el PLD se definía como la tercera fuerza política en términos electorales.

El desencanto de la población como reacción ante la imposibilidad de haber materializado las expectativas forjadas en la transición democrática y la emergencia de una crisis del liderazgo político eran las características del quehacer político dominicano a mediados de los años ochenta. 
Se asistía a un comienzo de decadencia y envejecimiento de los líderes tradicionales - Balaguer y Bosch-, frente a una regresión o retraimiento de los líderes modernos (Peña Gómez, Jorge Blanco, Majluta). Y en medio de esta pérdida de liderazgo político no se vislumbraban nuevos actores.

A la ceguera física de Balaguer se unía la ceguedad que confiere la personalidad carismática, que ha mantenido la antiinstitucionalidad del PR impidiéndole desarrollar una estructura pluralista legitimada por identidades e intereses diferentes a los del «líder carismático».

Por lo que, no obstante haber adoptado el PR la ideología social cristiana ", su estructura interna seguía operando en función de un movimientismo, en el cual la unidad e identidad de sus integrantes existe única y exclusivamente en función de la presencia del sólido liderazgo carismático de Balaguer, lo que le ha permitido mantener el apoyo constante de sus electores tradicionales (mujeres y campesinos).

Del otro lado del espectro político se encontraba Bosch, quien, a pesar de su avanzada edad ${ }^{12}$, no estaba desgastado por el poder $y$ desde las elecciones de 1982 había empezado a reforzar su antiguo liderazgo político entre sectores laborales.

No obstante, la estructuración del PLD como partido de cuadros con una dirección totalmente centralizada e ideológicamente cohesionada en torno al líder ("el maestro") y su doctrina, impedía vislumbrar la emergencia de un nuevo liderazgo político dentro del partido que diera continuidad a su popularidad dentro de las masas, con cuyo apoyo se estaba consolidando su trayectoria como partido mayoritario.

A todo esto, el PRD, que había entrado en su etapa más crítica desde que a finales de los setenta iniciara la lucha de tendencias entre los diferentes sectores que se disputaban el liderazgo del partido, se encontraba en un estado caótico que promovía su total división, frente al debilitamiento del liderazgo de Peña Gómez.

El detonante de la crisis lo constituyó el asalto a la Convención de 1985 por la tendencia jorgeblanquista que apoyaba la candidatura de $\mathrm{Pe}$ -

1 La fusión del Partido Reformista (PR) con el minoritario Partido Revolucionario Social Cristiano en 1984, permitió al PR formar parte de la Internacional Demócrata Cristiana.

${ }^{12}$ Juan Bosch y Joaquín Balaguer son dos líderes octogenarios: el primero tiene 80 años y el segundo 83 . Ambos han ejercido su liderazgo político desde la dictadura trujillista, Balaguer como delfín de Trujillo y Bosch como dirigente político en el exilio. 
ña Gómez a la presidencia del gobierno por el PRD, en contra de la tendencia de Jacobo Majluta, virtual ganador de las elecciones internas del partido antes de la suspensión del conteo de los votos, como resultado del «concordazo» ${ }^{13}$.

Por otro lado, la izquierda, representada básicamente por el Partido Comunista Dominicano (PCD) de Narciso Isa Conde, se encontraba dividida, por lo que no obstante su participación en el sistema, estaba imposibilitada para impulsar mecanismos propios de adhesión y organización de las masas.

Por lo que Balaguer, anciano y prácticamente ciego, pero astuto y habilidoso, explotaba la experiencia de sus cincuenta años en la vida política -que lo había convertido en un gran conocedor de la mentalidad del pueblo dominicano, fruto en gran parte de la cultura autoritaria que él, como actor principal, había forjado- ofreciendo propuestas pragmáticas al desencanto que habia despertado en la población la política corrupta y clientelista del PRD.

A la desmoralización generada por la corrupción administrativa de los perredeístas, Balaguer ofrecía una recuperación de los valores morales de la sociedad dominicana.

Para encarar la crisis económica que enfrentaba el Estado con la presión de la deuda externa y con la crisis interna generada por las políticas fondomonetaristas aplicadas por el gobierno de Jorge Blanco, Balaguer proponía un relanzamiento de la economía mediante el ahorro interno, la eficiencia administrativa y la recuperación de la soberanía nacional.

Propuesta esta última que estaba dirigida a restaurar el orden político que había sido convulsionado por las luchas internas en el PRD, que habían promovido en gran parte la crisis económica y política.

El triunfo electoral de Balaguer en las elecciones de 1986 fue la respuesta de la mayoría al desencanto generado por el sueño democrático no realizado.

De ahí que el proyecto político del quinto gobierno balaguerista se fundamentaría en tres puntos básicos: la confianza en la honestidad de

13 La crisis producida por el "concordazo" fue resuelta mediante un acuerdo conocido como el "Pacto la Unión", celebrado en 1986, en el que los arreglos personales entre los líderes de las distintas tendencias se antepusieron a los mecanismos democráticos de decisión, lo que terminó por quebrar la unidad del PRD hasta su total desintegración. 
los servidores públicos, la defensa de un sistema libre de empresas sin privilegios ni favoritismo y la conciliación política en una democracia participativa, basada en el "orden" y la "libertad" como elementos constitutivos de una política equilibrada de las instituciones del Estado, según la interpelación hecha en su discurso de toma de poder.

Para el cumplimiento del primer objetivo y a fin de «devolver la confianza y la honestidad perdidas", Balaguer inició un "proceso de rendición de cuentas" contra los actos deshonestos cometidos por los funcionarios de la última administración perredeísta, empezando por el expresidente Jorge Blanco, el ex-ministro de Defensa y el más importante "asesor económico" del ex-presidente, Leonel Almonte ${ }^{14}$, contra quienes se realizó el "juicio del siglo». El cual se convirtió en un fuerte mecanismo legitimador del proyecto político de Balaguer, con el que no solamente logró la aceptación de las reglas de procedimiento de su régimen por parte de sus tradicionales seguidores, sino también su reconocimiento y apoyo entre sectores sociales que habían rechazado su política de los doce años.

El «juicio" y la "rendición de cuenta» supeditaron en gran parte la legitimación del régimen por una mayoria importante de la población (básicamente los sectores populares), a una manipulación de los procedimientos democráticos, mediante instituciones de control capaces de formar opinión y colocar su sello en la conciencia de una sociedad saturada por los actos de corrupción de sus dirigentes políticos. Pues no hay que olvidar que la corrupción fue determinante en la opción de una mayoría del electorado por la reinserción del liderazgo personalista de Balaguer, quien como gran conocedor de la mentalidad del pueblo dominicano y en un claro intento por consolidar su régimen, explotado en su beneficio, factores como el bajo nivel educacional, la prensa y sobre todo su carisma. Logrando con ello desviar la atención de la sociedad de las debilidades de su gobierno.

Para cumplir con su segundo objetivo, "la defensa de un sistema de libre empresa y el ahorro interno" como herramientas prioritarias del desarollo, Balaguer intentó restablecer los fundamentos prácticos del "keynesianismo dominicano", basado en el papel activo del Estado en la economía mediante un programa de gastos públicos dirigido a la "expansión» y al "crecimiento", cuya esencia radica en un enorme proyecto de construcción, por oposición a la modificación estructural del aparato productivo.

14 El Secretario General de las Fuerzas Armadas durante el gobierno de Salvador Jorge Blanco (1982-1986) era el General Manuel Antonio Cuervo Gómez. Mientras el "asesor económico" del presidente era Leonel Almonte, quien en calidad de testaferro había ascendido de vendedor de enciclopedias (tocando puertas) a propietario de un sinnúmero de bancos, periódicos, cadenas de radio y televisión. 
La construcción de obras en su mayoría suntuorias ${ }^{15}$, estaba a su vez dirigida a crear paliativos contra el desempleo, mientras las canastas populares (fundas de alimentos) y los comedores económicos combatían contra lo que él llamó utiranía de la miseria». Mientras se agudizaba la depreciación monetaria del peso dominicano que agudizaba la inflación y que concentraba el ingreso en pocas manos: el sector importador y el sector especulativo.

Las expectativas económicas en 1989 eran de un considerable aumento inflacionario en los años siguientes, como resultado de los excesivos gastos públicos y de la actividad especulativa, lo que promovía una cada vez mayor devaluación de la moneda, mientras la política de programas recesivos ejecutados a instancias del FMI, desataban movilizaciones de protesta en contra de la aplicación de nuevos programas de ajustes económicos.

El tercer objetivo, la conciliación política, para la cual Balaguer propuso una «tregua» de dos años, traducía el intento de perpetuación de Balaguer en el poder, mediante la identificación de su propia supervivencia política con la del régimen. De ahí que la relación en el lenguaje político de dos términos diametralmente opuestos, algo propio de la retórica discursiva de Balaguer, no era sorprendente, si se tomaba en cuenta el momento político que estaba viviendo el país al iniciarse el nuevo período de gobierno, sumado a una crisis económica de resultados imprevisibles a la que Balaguer, en su «imposibilidad de hacer milagros", parecía temer.

En este sentido, la relación hecha entre "tregua" y "conciliación", mediante el cual pretendía Balaguer reducir cualquier tipo de reclamo que estuviese en contra de su proyecto de "orden" y "libertad". El "orden" concebido como un valor imprescindible y la "libertad" como algo accesorio, que además es incompatible con el "progreso". De ahí que el "orden" es concebido como ausencia de oposición ("anarquía») a fin de mantener la estabilidad política.

En su quinto gobierno, Balaguer intentó borrar su imagen del pasado, de ese pasado que lo identificaba con la represión, con la negación de los derechos políticos, con la violencia en todas sus manifestaciones. De ahi las medidas tomadas a fin de legitimarse políticamente entre sectores populares urbanos, la juventud universitaria y la izquierda, co-

15 La obra más suntuaria iniciada por Balaguer es la construcción en la capital dominicana, Santo Domingo, de un monumento al «descubrimiento y evangelización de América", el faro a Colón, con el cual pretende Balaguer perpetuarse en la memoria del pueblo dominicano. 
mo fue el desafío hecho a los militares para que recuperaran los restos de Caamaño, líder constitucionalista asesinado durante el régimen balaguerista de los doce años, al que declaró «héroe nacional por su defensa de la soberanía frente a las tropas norteamericanas».

De esta manera intentaba Balaguer sobrevivir a los mitos, a fin de convertir sus acciones personales en mitos y los mitos en hechos supeditados a la fragilidad de la memoria, al reivindicar un importante anhelo de la población, que, en eterno agradecimiento, le despojaría de toda responsabilidad sobre hechos negativos del pasado, lo que terminaría por limpiar su imagen hasta perpetuarla.

\section{¿Logró Balaguer en su quinto gobierno el consenso pasivo mediante el cual interpeló a la población en torno a su objetivo de búsqueda de la «conciliación»?}

Para reafirmar su imagen mesiánica entre sus tradicionales sectores de apoyo (campesinos, mujeres, sectores urbanos marginados), Balaguer retornó al uso de los mecanismos de adhesión del pasado: recorrido semanal e ininterrumpido por todo el país para escuchar las quejas de la población, de los campesinos sin tierra y las necesidades domésticas de las masas populares, para cuya solución daba órdenes inmediatas a sus funcionarios, a quienes criticaba públicamente por sus ineficiencias.

De esta forma, ordenaba el reparto de tierras, fustigaba a los terratenientes y reconocía públicamente la complicidad de los militares con éstos últimos, acusándoles de violar los derechos de los campesinos.

Con su política de arrastre, pretendía el líder carismático reducir las mediaciones entre el Estado y la sociedad a prácticas políticas de relaciones personales, en las que las decisiones y la participación estaban cada vez más restringidas.

Su política personalista promovió un movimientismo en el que la relación directa entre el Estado y la sociedad civil intentaba sobrepasar el marco institucional del espacio político, que se encontraba debilitado debido a la fragmentación de las formas convencionales de participación. Todo ello, fruto de la crisis de liderazgo que había emergido a finales de los años setenta y que se reforzó en los ochenta con la división del PRD, frente a la continuidad de las prácticas políticas autoritarias del PR, lo que obstaculizaba la actividad de los partidos políticos como mediadores de los intereses y conflictos entre la sociedad y el Estado. 
No obstante, la crisis de los partidos políticos promovió el surgimiento de nuevas formas de participación que habían encontrado su máxima expresión en las huelgas y protestas de 1984, originadas por la crisis económica y las medidas fondomonetaristas del gobierno de Jorge Blanco, y que se reforzaron durante el gobierno de Balaguer hasta constituirse en importantes mecanismos de mediación política.

Ejemplo de ello fue el surgimiento del liderazgo popular de Virtudes Álvarez, quien se constituyó en vocero de un movimiento popular denominado Consejo de Unidad Popular, cuyas actividades reivindicativas por la implementación de medidas económicas en beneficio de los sectores mayoritarios repercutieron de manera importante en la sociedad.

La capacidad organizativa de este movimiento social llegó a trascender de tal manera, por su efectividad en las convocatorias de huelgas y manifestaciones populares, que a los sectores que originalmente lo integraban (desempleados, trabajadores) se adhirieron capas medias y pequeño empresariado.

De esta manera, el Consejo de Unidad Popular pasaría a formar parte de un gran frente de masas, la Conferencia de Organizaciones Populares.

Las principales reivindicaciones de dicho movimiento popular -modificación de la política económica, rebaja de los artículos de primera necesidad y reajuste salarial- llegaron a atraer de tal manera la participación popular, que el presidente Balaguer, preocupado por las repercusiones sociales del mismo, intentó crear un sentimiento de «solidaridad vertical" que vinculase a Virtudes Álvarez con el presidente, en base al reconocimiento en la líder de una personalidad carismática y de unos valores mesiánicos, a fin de provocar en ella sentimientos afectivos que debilitasen los antagonismos entre la organización popular y el gobierno, hasta producir la desarticulación del movimiento como mecanismo mediador de conflictos.

Mientras, los empresarios, representantes en el Consejo Nacional de Hombres de Empresa (CNHE), promovían mecanismos de concertación social con los sindicatos, a fin de crear antagonismos entre éstos y el movimiento popular, para dividirlo.

A todo esto, la crisis de los partidos políticos, cuya implosión más detonadora fue la división del PRD, resultado de un proceso de crisis del liderazgo político generado por el retorno al uso de formas autoritarias de organización interna, se materializó formalmente antes de las elecciones de 1990 - luego de un largo período de intensas luchas entre las tenden- 
cias de Majluta y de Peña Gómez-, cuando la Junta Central Electoral adjudicó la presidencia del PRD a Peña Gómez y Majluta formó su propia organización, el Partido Revolucionario Independiente (PRI) ${ }^{16}$.

La crisis interna del principal partido en la oposición puso de manifiesto la indiferencia de sus líderes ante los problemas nacionales, de tal forma que, durante el gobierno de Balaguer (1986-1990), el poder mediador de los partidos políticos quedó subordinado a los nuevos movimientos sociales, que fueron los únicos dispuestos a enfrentarse con la política económica del gobierno, mientras los partidos esperaban básicamente a conquistar el apoyo popular en las elecciones, a fin de revalidar las élites en el poder.

La política económica estatista y expansionista de Balaguer produjo, a finales de los ochenta, fuertes tensiones entre el gobierno y los sectores empresariales agrupados en el CNHE, las cuales desembocaron en la disminución del apoyo de los empresarios al proyecto económico de Balaguer, cuyo saldo final fue el descontento manifiesto de la clase empresarial por la inflexión de la postura intervencionista del Estado.

A saber, desde finales de los años setenta, la clase empresarial dominicana había empezado a considerar el intervencionismo estatal como un obstáculo a su expansión.

Inspirada en la tendencia hacia el neoconservadurismo que había empezado a producirse a mediados de la década en los países desarrollados, la intelligentsia tecnocrática dominicana construyó su política de emancipación de los mecanismos económicos del control estatal.

La formalización la hizo inicialmente el CNHE durante los gobiernos perredeístas, en virtud de la cual se promovió la negociación entre el gobierno de Jorge Blanco y el FMI del Acuerdo de Facilidad Ampliada, que facilitó la ejecución de la política de liberalización de la economía mediante la expansión de las actividades especulativas sobre las productivas.

Pero a pesar de las presiones ejercidas por el CNHE sobre el gobierno de Balaguer, éstas no impidieron la ejecución de su proyecto expansionista sustentado sobre la base de las inversiones públicas, política que ha resultado tan dañina para el país como la promovida por los neoliberales criollos. Pues el modelo económico y político neoliberal persigue

${ }_{16}$ Jacobo Majluta fue el candidato a la presidencia por el PRD en las eleccciones de 1986, después de resuelto el impasse producido por el asalto a la Convención de 1985 (el "concordazo"). 
la salvaguarda de una esfera estatal más restringida e instituciones políticas menos "sobrecargadas", vía la reconstitución de una sociedad civil que ya no dependa de una regulación, control e intervención del Estado.

El proyecto político y económico neoconservador se traduce, pues, en la emancipación de la sociedad civil del Estado, cuya consolidación es impensable en la República Dominicana, en donde la práctica económica ha estado determinada desde finales de los años setenta por la promoción de las actividades especulativas sobre las productivas. Lo que ha promovido el individualismo, la distribución injusta del ingreso vía el enriquecimiento de unos pocos en perjuicio de la mayoría, así como la quiebra o cierre de algunos sectores productivos ante las ventajas de las actividades especulativas, lo que ha generado, a su vez, una situación de desempleo endémico.

En la República Dominicana, promover la liberalización de los fenómenos económicos (salarios, precios, comercio exterior, tipos de interés, etc.) supondría la plena libertad del empresariado, lo que generaría ganancias ilimitadas a costa de la injusticia social.

Los principales problemas de la población dominicana son aquellos que no son siquiera imaginables en los países del capitalismo avanzado donte tuvo su nacimiento la teoría neoliberal como nuevo paradigma político y económico. A saber, la escasez de energía eléctrica, la falta de agua potable, deficiencias en el transporte, en los servicios públicos, en la salud y en la educación, frente a una cada vez mayor espiral inflacionaria y solidez de las actividades especulativas.

Además de estos factores, que limitan la consolidación de la democracia en la República Dominicana, hay que resaltar las debilidades del sistema electoral y la necesidad imperiosa de su reforma, a fin de garantizar la institucionalidad del sistema político.

Se precisa de manera urgente la creación de un sistema que no limite la voluntad de los electores, que dé la oportunidad al elector de conocer cuáles son sus representantes en el Congreso Nacional (Senado y Cámara de Diputados).

Es necesaria la elaboración de una reforma constitucional que limite las extraordinarias funciones del Senado, ya que, además de las funciones legislativas, tiene como atribuciones exclusivas, el nombramiento de los jueces y de los miembros de la Cámara de Cuentas, razón por la cual el interés de los partidos políticos en obtener la mayoría senatorial ha dado lugar a crisis importantes en el actual proceso democrático. 
Pues la vinculación del Senado con el Ejecutivo han convertido al Congreso Nacional, no en un mecanismo de canalización y procesamiento de las demandas de la sociedad, sino en una caja de resonancia del Ejecutivo.

Mientras; la designación y subordinación de los miembros de la JCE al Ejecutivo ha dado lugar a irregularidades en el proceso electoral y a denuncias de fraude, dado su gran potencial de politización ${ }^{17}$.

\section{LAS ELECCIONES DE 1990: CRISIS DEL LIDERAZGO POLÍTICO}

La precampaña electoral de mayo de 1990 estuvo contenida de un simbolismo solamente comprensible en el contexto histórico de la cultura política dominicana, donde el personalismo y la desconfianza en las instituciones públicas, producto de actitudes corruptas, constituyen las bases sustentadoras de la conquista del poder del Estado, que impide cualquier intento de creación de un nuevo paradigma.

La convivencia en el proceso democrático de actitudes y sentimientos autoritarios en los actores políticos, contra la identificación de la sociedad con los mecanismos de institucionalización democrática, se puso de manifiesto, una vez más, en el último proceso electoral, generando tensiones de efectos altamente dañinos para la consolidación del sistema democrático.

La precampaña electoral se debatió entre un Balaguer ciego y octogenario que insistía en "remachar su sitio en la historia", proponiendo "seguridad" ante el "salto al vacío" que significaba (para él) el ascenso al poder de Bosch, y en la continuación de su política de gastos públicos dirigida a las construcciones; un Bosch igualmente octogenario, cuya condición mental planteaba serias dudas, y que prometía mejores salarios, luchar contra la inflación y la crisis energética, privatizar las empresas públicas deficitarias, racionalizar la administración pública, fomentar el turismo,

17 En las elecciones de 1986 hubo denuncia de fraude por parte del PRD, cuyo candidato a la presidencia, Jacobo Majluta, perdió frente a Balaguer por un escaso margen de votos del $1,93 \%$, lo cual puso de manifiesto una vez más la debilidad de la JCE como órgano encargado de dirimir el proceso y las deficiencias del sistema electoral, agravadas entonces por la introducción del sistema de boleta única. 
respetar las zonas francas y realizar reformas tributarias; y un Peña Gómez que basó su interpelación en un mensaje moderado y conciliador, asegurándose el respaldo internacional de los gobiernos de la Internacional Socialista y el apoyo de los sectores jorgeblanquistas. El cuarto candidato era Jacobo Majluta, cuyo programa de gobierno lo había identificado con el alto empresariado, pero cuya popularidad empezó a disminuir como resultado de la adjudicación por la JCE del PRD a Peña Gómez.

Mientras las encuestas daban la victoria a Bosch, éste buscaba ganarse el apoyo del empresariado y la obediencia de los militares en su "futuro" gobierno, mediante el ofrecimiento de mejores sueldos para las Fuerzas Armadas y la privatización de las empresas públicas deficitarias. Intentando por otra parte, contar con el apoyo de la Iglesia, mediante declaraciones en las que negaba su vinculación con el marxismo leninista.

Las denuncias de la preparación de un fraude electoral hecha antes de las elecciones por el PLD y el PRD, frente al temor de la emisión de cédulas falsas o la duplicación de las mismas para beneficiar al PRSC, enturbiaron las elecciones.

La respuesta de la JCE fue la paralización de las actividades de la Dirección General de Cédulas, a fin de evitar la solicitud y emisión de nuevas cédulas de identidad fuera de los plazos establecidos.

En un principio se estimaba que el fraude oscilaría entre los cien y los doscientos mil votos, mientras las encuestas indicaban, a unos días de las elecciones, expectativas electorales de 900.000 votos para el PLD de Bosch, 700.000 para el PRSC de Balaguer, 600.000 para el PRD de Peña Gómez y alrededor de los 150.000 para el PRI de Majluta.

Las posibilidades de formar alianza se habian planteado entre $\mathrm{Ba}$ laguer y Majluta y entre el último y Peña Gómez, pero las diferencias personales entre los candidatos, sobre todo entre Majluta y Peña Gómez, hizo fracasar las coaliciones.

A las denuncias de fraude se sumaba la precaria situación económica de la JCE y la amenaza de su presidente, Froilán Tavares, de dimitir, frente a las imposibilidad de utilizar los recursos necesarios para garantizar la credibilidad del proceso electoral. Situación que fue resuelta mediante una limitada subvención económica acordada por el gobierno.

Una vez terminadas las elecciones y ante la victoria electoral de Balaguer frente a Bosch, éste último denunció la comisión de un ufraude colosal» en favor de Balaguer. 
El recuento de los votos por una comisión nacional y una internacional dirigida por Carter, quien legitimó el conteo, permitió la finalización del proceso electoral y la aceptación de Bosch de su derrota por Balaguer con una diferencia de alrededor de 18.000 votos, con lo cual se puso de manifiesto, una vez más, la importancia del factor externo, Estados Unidos, en la «garantía del proceso democrático dominicano».

La reelección de Balaguer como Presidente de la República, legitimado por la mayoría de escaños en el Senado del PRSC ${ }^{18}$, supone el control por el partido oficialista del Poder Judicial y de la Junta Central Electoral (JCE) en los próximos cuatro años (1990-1994), lo que podría dificultar las posibilidades de reforma del sistema electoral, a fin de regenerar la confianza perdida por la población hacia sus instituciones políticas formales, al tiempo que limitaría la capacidad de canalización y procesamiento de las demandas sociales por el Poder Legislativo.

Por otro lado, el actual proceso de crisis del liderazgo político, plantea la necesidad de un consenso entre los líderes tradicionales que garantice la estabilidad del sistema, así como la promoción y emergencia de nuevos líderes en base a una mayor institucionalización del sistema de partidos vía la redefinición de la dinámica organizativa interna, que les permita responder a los desafíos del final de este "ciclo" histórico y avanzar hacia una nueva espiral política.

18 EI PRSC obtuvo 16 escaños en el Senado, frente a 12 del PLD y 2 del PRD. En la Cámara de Diputados, el PRSC obtuvo 41 escaños, el PLD 44, el PRD 33 y el PRI 2. Conviene precisar que la elección de los senadores se hace por mayoría simple - fórmula uninominal mayoritaria sobre la base de un senador por provincia, con independencia de su mayor o menor relevancia poblacional-, lo que determina la sobre-representación de los partidos mayoritarios frente a la no participación de terceros partidos. Mientras en la Cámara de Diputados la elección se hace mediante la fórmula proporcional, lo que permite una composición más equilibrada. 